

\section{Sumário}

A DISCRIMINAÇÃo RACIAL NO BRASIL E A ASCENSÃo DO POVO NEGRO: UM OLHAR A PARTIR DOS PRINCÍPIOS CONSTITUCIONAIS NA LUTA PELA CIDADANIA INCLUSIVA

Bruno Mello Correa de Barros e Rita Mara Albrecht

As MULHERES NO CONTEXTO DA SOCIEDADE DE CLASSES E SUA PARTICIPAÇÃO POLÍTICA NO PROCESSO LEGISLATIVO E EXECUTIVO DO BRASIL: RESTRIÇÕES E DESAFIOS

Rafael Bueno da Rosa Moreira e Marli Marlene Morais da Costa

FACTORES ASOCIADOS A LA VIOLENCIA DE GÉNERo EN PAREJAS ADOLESCENTES

Maria del Carmen Monreal Gimeno

Os IMPACTOS DAS TECNOLOGIAS DA INFORMAÇÃO NO FLUXO DE PESSOAS: VIOLAÇÕES DA LIBERDADE EM UM MUNDO SECURITIZADO

Elias Jacob de Menezes Neto, Jose Luis Bolzan de Morais e Victoria Layze Silva Fausto

El DELITO DE ENALTECIMIENTO TERRORISTA. ¿INSTRUMENTO DE LUCHA CONTRA EL PELIGROSO DISCURSO DEL ODIO TERRORISTA O MECANISMO REPRESOR DE REPUDIABLES MENSAJES DE RAPEROS, TWITTEROS Y TITIRITEROS?

Alfonso Galán Muñoz

As POLÍtiCAS PÚBLICAS E A PROMOÇão DA DIGNIDADE: UMA ABORDAGEM NORTEADA PELAS CApacidades (CAPABIlities APproach) propostas por Martha Nussbaum

Anna Paula Bagetti Zeifert e Janaína Machado Sturza

A INFLUÊNCIA DA MÍdia PARA O CONSUMO DE TABACO

Luís Renato Vedovato e Maria Carolina Gervásio Angelini

¿SON PARTE DEL BLOQUE DE CONSTITUCIONALIDAD LOS PRINCIPALES TRATADOS internacionales de derechos humanos de la ONU en Chile? Del texto positivo a la APLICACIÓN EN TRIBUNALES DE JUSTICIA Juan Pablo Díaz Fuenzalida

Potestad calificadora del Conservador de Bienes Raíces y Procedimiento Registral ....173 Sebastián Bozzo Hauri e Gonzalo Ruz Lartiga

DESARTICULAÇÃo INTERFEDERATIVA E CONCESSÃo DOS BENEFÍCIOS DE PRESTAÇÃo CONTINUADA (BPC) 
Aprendizagem Profissional e o poder público municipal: proposta de maior eficácia À POLÍTICA PÚBLICA

José Rodrigo Paprotzki Veloso

Direito A Conciliação Entre Trabalho E Família................................................229

Edilton Meireles de Oliveira Santos

Trabajo y diversidad funcional. La situación EN EL ORdenamiento JuRídico español 245 María Esther Carrizosa Prieto

Custos de TransaÇão como uma METAPolítica pública .........................................2276

João Luis Nogueira Matias e Ricardo José Brito Bastos Aguiar de Arruda

REVISITANDO O CONCEITO DE SERVIÇO PÚBLICO

Andre Luiz Dos Santos Nakamura

O Brasil FACE AOS NOVOS PADRÕES DE COMÉRCIO E INVESTIMENTO DOS ACORDOS INTERNACIONAIS

Michelle Sanchez Badin, Fabio Costa Morosini e David M. Trubek

Os contratos comerciais na Declaração dos Direitos de Liberdade Econômica (MP 881/19).

André Lipp Pinto Basto Lupi

O MARCO LEGAL DA INOVAÇÃO E O AUMENTO DA INTERAÇÃO ENTRE UNIVERSIDADE E EMPRESA: CONTRIBUIÇÕES PARA A CONSOLIDAÇÃO DO DIREITO FUNDAMENTAL AO DESENVOLVIMENTO ....352 Thiago Paluma e Eline Débora Teixeira

RELICITAÇÃo DAS CONCESSÕES DE GERAÇÃo DE ENERGIA ELÉTRICA E A REVERSÃo DE BENS....372 Patrícia Regina Pinheiro Sampaio e Sergio Guerra

FinANCIAMENTO TRANSGERACIONAL DA INFRAESTRUTURA VERDE FLORESTAL: O SISTEMA DE PAGAMENTO POR SERVIÇOS AMBIENTAIS COMO INSTRUMENTO DE GESTÃO DE RISCOS NA SOCIEDADE CONTEMPORÂNEA...................................................................................................390

Délton Winter de Carvalho e Kelly de Souza Barbosa

Mediação como Política Pública para Tratamento de Conflitos Consumeristas ..... 415 Fernanda Sartor Meinero e Fernando Pedro Meinero

A ParticipaÇão do AMICUS CURIAE EM DECISÕES JUdiCIAIS E SUA CONSEQUENTE CONTRIBUiÇÃo para efetivação de Políticas Públicas .429

Viviane Nobre Santana 
A ISONOMIA TRIBUTÁRIA COMO LIMITE À TRIBUTAÇÃo E À CONCESSÃO DE ISENÇÕES FISCAIS, E A INEFETIVIDADE DO CONTROLE JURISDICIONAL DESSAS ISENÇÕES..................................450

Paulo Alves da Silva Paiva e Alexandre Augusto Batista de Lima

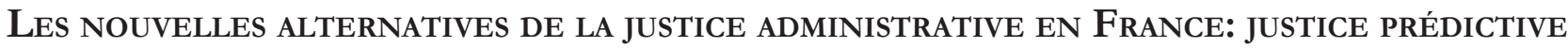
ET JUSTICE AMIABLE

Marie-Odile Diemer

O ESTADO DA LUXÚRIA: A PARÁBOLA DO BMW E A REAL DIMENSÃo DO DEBATE SOBRE A RESERVA DO POSSÍVEL: ESCASSEZ DE RECURSOS OU ORDENAÇÃo DE PRIORIDADES?................................484 Assis José Couto do Nascimento

O PODER CONSTITUINTE

José Levi Mello do Amaral Júnior

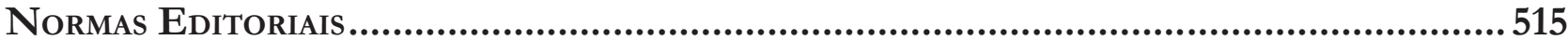

Envio dos trabalhos: 


\title{
O marco legal da inovação e o aumento da interação entre universidade e empresa: contribuiç̧̃̃es para a consolidação do direito fundamental ao desenvolvimento*
}

\author{
Legal framework for innovation and \\ the increment of interaction between \\ university and company: contributions for \\ the consolidation of the fundamental right to \\ development
}

\section{Resumo}

O presente artigo aborda as principais mudanças trazidas pela Lei da Inovação (Lei 10.973/2004), posteriormente modificada pelo Marco Legal da Inovação (Lei 13.243/2016), no que tange aos seus reflexos para o aumento da interação entre as universidades e as empresas, na perspectiva da consolidação do direito fundamental ao desenvolvimento. Adotar-se-á, ao longo deste estudo, o conceito de desenvolvimento de Amartya Sen, que consiste em uma perspectiva mais ampla e integrada entre desenvolvimento não apenas econômico, mas também social, com base no aumento das liberdades individuais. Ademais, abordar-se-á o referido conceito para se conceber o direito ao desenvolvimento como um verdadeiro direito fundamental. $\mathrm{O}$ objetivo geral do presente estudo consiste em analisar em que medida o aumento da interação entre universidade e empresa pode contribuir para a consolidação do direito fundamental ao desenvolvimento, por meio de uma análise crítica da referida legislação e das políticas públicas estabelecidas a partir dela. O método de abordagem é o dedutivo, com base na análise dos principais pontos da legislação ordinária nos quais ocorreram mudanças no que diz respeito ao aumento da interação entre universidade e empresa, e como essas mudanças podem promover a consolidação do direito fundamental ao desenvolvimento, como um direito constitucionalmente e garantido. Conclui-se que a mera positivação do direito fundamental ao desenvolvimento é insuficiente por si só, do ponto de vista prático, para sua consolidação, carecendo de efetivas ações promocionais voltadas para a criação e o aprimoramento de políticas públicas que efetuem a democratização dos espaços dos NITs.

Palavras-chave: Marco legal da inovação. Direito ao desenvolvimento. Universidades. Empresas.

*** Mestranda em Direito pela Universidade Federal de Uberlândia. Professora do Centro Universitário Patos de Minas-UNIPAM. E-mail: elinedeborah@gmail.com.
** Doutor em Direito pela Universidade de Valencia. Professor da Faculdade de Direito da Universidade Federal de Uberlândia. E-mail : thiago.paluma@ufu.br.

* Recebido em 17/08/2018 Aprovado em 01/11/2018 


\section{Abstract}

This article deals with the main changes brought about by the Innovation Law (Law 10.973 / 2004), later modified by the Legal Framework for Innovation (Law 13243/2016), regarding its effects on the increase of interaction between universities and companies, with a view to consolidating the fundamental right to development. Throughout this study the concept of Amartya Sen's development will be adopted, which consists of a broader and more integrated perspective between development not only economic but also social, based on the increase of individual freedoms. In addition, this concept will be considered as a background to conceive the right to development as a true fundamental right. The general objective of the present study is to analyze to what extent the increased interaction between university and business can contribute to the consolidation of the fundamental right to development, through a critical analysis of said legislation and the public policies established by it. The method of approach is the deductive, based on the analysis of the main points of ordinary legislation in which changes have taken place in increasing the interaction between university and company, and how these changes can promote the consolidation of the fundamental right to development, as a constitutionally guaranteed right. It is concluded that the mere affirmation of the fundamental right to development is insufficient in itself, from a practical point of view, for its consolidation, lacking effective promotional actions aimed at the creation and improvement of public policies that effect the democratization of the spaces of the NITs.

Keywords: Legal Framework for Innovation. Right to development. Universities. Companies.

\section{Introdução}

O Marco Legal da Inovação (Lei 13.243/2016) positivou, em seu artigo 1º parágrafo único, inciso I, o Princípio da Necessidade de Promoção de Atividades Científicas e Tecnológicas como estratégias para a promoção do desenvolvimento socioeconômico.

Contemporâneo à novidade legislativa, tem-se o relatório econômico OCDE Brasil 2018², em que o Brasil mantém-se como uma das maiores economias do mundo, mas com um abismo social marcado pela desigualdade. Ou seja, a realidade brasileira é de crescimento econômico, ainda que reduzido nos últimos anos, apartado de desenvolvimento social.

O descompasso entre o crescimento econômico e o desenvolvimento brasileiro constitui justificativa para pesquisar os impactos da legislação que cria incentivos para a interação entre universidade e empresa, e o papel destinado aos Núcleos de Inovação Tecnológica - NITs com base no Marco Legal da Inovação, como influenciadores ou propulsores de desenvolvimento econômico e social.

Diante disso, a presente pesquisa tem por escopo responder à seguinte problemática: como o aumento da interação entre universidade e empresa, positivada pelo Marco Legal da Inovação, contribui para a consolidação do direito ao desenvolvimento como um direito fundamental?

A hipótese que se trabalha consiste no aumento da interação entre universidade e empresa com base no Marco Legal da Inovação. Tem como objetivo específico promover a consolidação do direito fundamental ao desenvolvimento. Ainda nessa seara, será abordada a necessidade de democratização dos espaços de conexão entre universidade e empresa, de forma que a mera positivação desse aumento da interação não constitui garantia de sua realização, sendo necessárias políticas públicas com ações promocionais do Direito

ORGANIZAÇÃO PARA A COOPERAÇÃO E DESENVOLVIMENTO ECONÓMICO. Relatórios econômicos OCDE: Brasil 2018. Paris: Éditions OCDE, 2018. Disponível em: <http://dx.doi.org/10.1787/9789264290716-pt>. Acesso em: 17 jul. 2018. 
estruturado $^{2}$, pós-disciplinares ${ }^{3}$, voltadas à consolidação dessa relação.

O presente trabalho parte da Teoria do Desenvolvimento como liberdade de Amartya $\mathrm{Sen}^{4}$, como pano de fundo para se conceber o direito ao desenvolvimento como disciplina a ser tratada não apenas pela economia, com sua racionalidade voltada para o lucro. Neste trabalho, pretende-se fundamentar o direito ao desenvolvimento como um verdadeiro direito fundamental, de forma que a sua realização não consista, meramente, em aumento de riquezas, sendo necessária, também, a consolidação do direito às liberdades individuais para o desenvolvimento pleno.

Assim, o objetivo geral da presente pesquisa consiste em estabelecer o aumento da interação entre universidade e empresa como meio para contribuir, funcionalmente, com a consolidação do direito fundamental ao desenvolvimento, para além da mera estrutura de positivação no ordenamento jurídico brasileiro, por meio da análise crítica da evolução legislativa e das políticas públicas estabelecidas a partir da lei em questão.

No primeiro tópico, analisar-se-á o surgimento da legislação reguladora da inovação no Brasil e sua evolução. Serão abordadas as principais modificações voltadas para o aumento da interação entre universidade e empresa, e como essas modificações geraram o aumento da segurança jurídica nas atividades realizadas em conjunto.

No segundo tópico, cumpre fundamentar o direito ao desenvolvimento como verdadeiro direito fundamental irrenunciável, com base na Teoria do Desenvolvimento como liberdade e na teoria geral e clássica dos direitos fundamentais. Ademais, relacionar-se-á o aumento da interação entre a universidade e a empresa com a consolidação do direito fundamental ao desenvolvimento, com base na necessidade de aprimoramento e efetivação das políticas públicas nas universidades.

Para enfrentar a problemática proposta, utilizar-se-á o método de abordagem dedutivo, uma vez que serão analisados os principais pontos da legislação ordinária nos quais ocorreram mudanças no que diz respeito à interação entre universidade e empresa, e como essas mudanças podem promover a consolidação do direito fundamental ao desenvolvimento, como um direito constitucionalmente garantido.

Não obstante, utilizar-se-á o método de procedimento histórico, por meio de um panorama da evolução normativa em âmbito nacional e alguns instrumentos internacionais relativos ao direito fundamental ao desenvolvimento ${ }^{5}$. Como técnicas de pesquisa, adotar-se-á a pesquisa bibliográfica e a análise documental, com enfoque para documentos relacionados que refletem direta ou indiretamente o desempenho do direito ao desenvolvimento no Brasil por meio de políticas públicas específicas ${ }^{6}$.

\section{A interação entre universidade e empresa: da Lei de Inovação ao marco legal da inovação}

Neste tópico, analisar-se-á o surgimento da legislação reguladora da inovação no Brasil, com foco na

2 BOBBIO, Norberto. Da estrutura à função: novos estudos de teoria do Direito. Barueri: Manole, 2007.

3 SOLSONA, Gonçal Mayos. Empoderamiento Y desarrollo humano: actuar local y pensar postdisciplinarmente. In: DÍAZ, Yanko Moyano et al. Postdisciplinariedad y desarrollo bumano: entre pensamiento y política. Barcelona: Linkgua, 2014. p. 189.

4 O presente artigo utiliza como marco teórico a obra SEN, Amartya. Desenvolvimento como liberdade. São Paulo: Companhia das Letras, 2000.

5 BITTAR, Eduardo C. B. Metodologia da pesquisa jurídica. 13. ed. São Paulo: Saraiva, 2015.

6 PRODANOV, Cleber Cristiano; FREITAS, Ernani Cesar de. Metodologia do trabalho cientifico: métodos e técnicas da pesquisa e do trabalho acadêmico. 2. ed. Novo Hamburgo: Feevale, 2013. 
interação entre universidade e empresa, com a Lei da Inovação. Posteriormente, as principais modificações trazidas recentemente pelo Marco Legal da Inovação serão analisadas, bem como pelo Decreto $n^{\circ}$ 9.283/2018, que teve como finalidade regulamentar a legislação ordinária. 


\subsection{Lei de Inovação e as dificuldades de interação entre universidade e empresa}

A Lei de Inovação (Lei 10.973/2004), promulgada em dezembro de 2004, positivou, dentre os seus principais objetivos, a transferência de tecnologia entre universidades e empresas. Ademais, positivou-se no referido diploma legal o direito de exploração dos royalties sobre os licenciamentos de qualquer espécie de propriedade intelectual (marcas, patentes, programas de computador, dentre outros) ${ }^{7}$. Segundo Denis Barbosa $^{8}$, algumas criações não estão inseridas na proteção da Lei de Inovação, que possui foco apenas nas criações de caráter tecnológico?. Tais criações são protegidas e reguladas por diplomas legais específicos.

A Lei de Inovação brasileira, quando de sua promulgação, foi estruturada em sete capítulos. Quatro capítulos foram voltados para a atividade inovativa ${ }^{10}$ em diferentes ambientes, quais sejam: estímulo à construção de ambientes especializados e cooperativos de inovação; estímulo à participação das ICTs no processo de inovação; estímulo à inovação nas empresas; estímulo ao inventor independente. Ademais, a Lei de Inovação deu grande espaço ao estímulo para a interação entre a universidade e a empresa. De fato, 15 dos seus 29 artigos já regulavam as bases de estímulo a essa questão ${ }^{11}$.

No processo de interação entre universidade e empresa, merecem destaque o artigo $4^{\circ}$, que estabeleceu as regras sobre a utilização dos laboratórios e das instalações das universidades com as empresas; o artigo $8^{\circ}$, que estabeleceu as regras sobre a prestação de serviços por ICTs a instituições privadas; e, o artigo $9^{\circ}$, que estabeleceu as regras sobre acordos de parceria entre ICTs e instituições privadas para o desenvolvimento tecnológico ${ }^{12}$.

A referida lei estabeleceu o conceito de ICT, como "órgão ou entidade da administração pública cuja missão institucional seja preponderantemente voltada à execução de atividades de pesquisa básica ou aplicada de caráter científico, tecnológico ou de inovação". Nesse sentido, universidades são espécies de ICTs. Estabeleceu, também, o conceito de NIT, como "núcleo ou órgão constituído por uma ou mais ICT com a finalidade de gerir sua política de inovação" ${ }^{13}$.

Esses conceitos foram pioneiros, marcando, definitivamente, uma nova era para a inovação no Brasil e estabelecendo política pública muito importante, que foi a implantação de núcleo especializado, o NIT, dentro de ICTs, com a função de, além de gerir a política de inovação, estabelecer e fomentar a interação da Pesquisa, Desenvolvimento e Inovação - PD\&I da universidade com as empresas. Na realidade, algumas

BRASIL. Lei no 10.973, de 2 de dezembro de 2004. Dispõe sobre incentivos à inovação e à pesquisa científica e tecnológica no ambiente produtivo e dá outras providências. Diário Oficial da República Federativa do Brasil, Brasília, DF, 3 dez. 2004. Disponível em: < http://www.planalto.gov.br/ccivil_03/_ato2004-2006/2004/lei/110.973.htm>. Acesso em: 22 jun. 2018.

8 BARBOSA, Denis Borges et al. Direito da inovação: comentários à Lei no 10.973/2004, lei federal da inovação. Rio de Janeiro: Lumen Juris, 2006. p. 21.

9 A Lei de Inovação traz um arcabouço de conceitos atinentes à área da PD\&I, definindo, especificamente, o que entende por criação: "invenção, modelo de utilidade, desenho industrial, programa de computador, topografia de circuito integrado, nova cultivar ou cultivar essencialmente derivada e qualquer outro desenvolvimento tecnológico que acarrete ou possa acarretar o surgimento de novo produto, processo ou aperfeiçoamento incremental, obtida por um ou mais criadores". ARAÚJO, Nizete Lacerda et al. Marco legal da inovação: breves comentários. Rio de Janeiro: Lumen Juris, 2018.

10 A Lei de Inovação aproxima-se do conceito dado pelo Manual de Oslo à inovação. Portanto, inovação é o desenvolvimento de um produto, de um produto ou um processo ou de um serviço de forma diferente da já conhecida e pronto para ser colocado no mercado. Difere-se do conceito de invenção, que consiste em uma ideia nova que leva à solução prática de um problema tecnológico inédita. ARAÚJO, Nizete Lacerda et al. Marco legal da inovação: breves comentários. Rio de Janeiro: Lumen Juris, 2018. p. 114.

11 BRASIL. Lei n ${ }^{\circ}$ 10.973, de 2 de dezembro de 2004. Dispõe sobre incentivos à inovação e à pesquisa científica e tecnológica no ambiente produtivo e dá outras providências. Diário Oficial da República Federativa do Brasil, Brasília, DF, 3 dez. 2004. Disponível em: < http://www.planalto.gov.br/ccivil_03/_ato2004-2006/2004/lei/110.973.htm>. Acesso em: 22 jun. 2018.

12 BRASIL. Lei no 10.973, de 2 de dezembro de 2004. Dispõe sobre incentivos à inovação e à pesquisa científica e tecnológica no ambiente produtivo e dá outras providências. Diário Oficial da República Federativa do Brasil, Brasília, DF, 3 dez. 2004. Disponível em: < http://www.planalto.gov.br/ccivil_03/_ato2004-2006/2004/lei/110.973.htm>. Acesso em: 22 jun. 2018.

13 BRASIL. Lei no 10.973, de 2 de dezembro de 2004. Dispõe sobre incentivos à inovação e à pesquisa científica e tecnológica no ambiente produtivo e dá outras providências. Diário Oficial da República Federativa do Brasil, Brasília, DF, 3 dez. 2004. Disponível em: < http://www.planalto.gov.br/ccivil_03/_ato2004-2006/2004/lei/110.973.htm>. Acesso em: 22 jun. 2018. 
Instituições Federais de Ensino Superior - IFES já dispunham dessa modalidade de setor, a formalização legislativa ocorre apenas em $2004^{14}$.

Após a implementação da legislação de 2004 nota-se a necessidade de reformulação dos conceitos legais, assim como a necessidade de otimização das políticas de interação estabelecidas pela referida legislação, a fim de tornar a Lei de Inovação um verdadeiro eixo jurídico-institucional pensado para fortalecer as áreas de PD\&I no Brasil.

A partir dessa necessidade, a Lei de Inovação é alterada pela Lei 13.243/2016, mais conhecida como Marco Legal da Inovação. A nova legislação aumenta a autonomia universitária no estabelecimento de relações com empresas, com o intuito de melhorar a interação entre esses entes, estimulando as ações conjuntas de PD\&I, a proteção da propriedade intelectual e a transferência de tecnologia. Não obstante a nova previsão legislativa, verificou-se, com base em relatórios de órgãos oficiais ${ }^{15}$, que essa interação, ainda, caminha de maneira muito tímida e abaixo do esperado.

Ademais, as universidades públicas brasileiras possuem um padrão de produção de conhecimento que consiste basicamente em estabelecer linhas de pesquisa dissociadas dos interesses do setor privado, produzindo, assim, como resultados de suas atividades, a produção de artigos científicos em periódicos indexados ou de pesquisas sem aplicação industrial. Trata-se, conforme a agenda "Produtivismo includente: empreendedorismo vanguardista" "16, apresentada pela Secretaria de Assuntos Estratégicos (SAE) para o desenvolvimento do país, do reflexo de um sistema de incentivos que privilegia a quantidade de publicações em detrimento de atividades de maior efeito prático, e que tem como base os critérios uniformes de avaliação institucional e de desempenho individual de seus pesquisadores e professores.

O efeito desses mecanismos de incentivo consiste em impor uma barreira que impede a valorização das pesquisas mais práticas e de maior impacto, distanciando os pesquisadores e as ICTs do mercado e da sociedade civil. Ademais, a própria Lei de Inovação, em sua forma original, era carente de definições claras sobre as boas práticas e o modo de operação e gestão da inovação por ICTs e sobre a forma ideal de parceria com as empresas privadas.

Bobbio ${ }^{17}$ já abordava a necessidade da função promocional do Direito, que deve adequar a sua teoria geral às transformações da sociedade contemporânea. Nesse contexto, para o autor, o Direito deve ser inserido na sociedade como um fenômeno dinâmico, promocional, composto por uma humanidade destinada ao bem comum e à realização individual promovida pelo Estado bonificador, e não mais apenas sancionador e repressor.

\footnotetext{
14 ARAÚJO, Nizete Lacerda et al. Marco legal da inovação: breves comentários. Rio de Janeiro: Lumen Juris, 2018. p. 9.

15 Essas dificuldades podem ser constatadas com base na interpretação de alguns estudos empíricos, produzidos por órgãos estatais responsáveis por esse controle, como os Relatórios anuais tanto do Instituto Nacional de Propriedade Intelectual - INPI quanto do Ministério da Ciência, Tecnologia e Inovação - MCTI (Formict). O Formict é um relatório produzido pelo MCTI para atender ao art. 17 da Lei de Inovação, o qual dispõe que as ICTs públicas deverão prestar informações anuais ao MCTI. Da interpretação desse relatório, observa-se um crescimento na implementação da política de inovação, mas permanece a dificuldade de implementação de algumas atividades da política de inovação, especialmente aquelas ligadas ao empreendedorismo, gestão de incubadoras e participação no capital social de empresas. Com base no relatório de atividades do Instituto Nacional de Propriedade Industrial - INPI, no ano de 2017, foram depositados 28.667 pedidos de patente. Desse total, o Brasil ocupa o segundo lugar no ranking da origem dos depositantes de patentes de invenção no Brasil (21\%), perdendo para os Estados Unidos da América (31\%). Ademais, no Brasil, apenas $24 \%$ desses pedidos foram originados das Instituições de Ensino e Pesquisa - ICTs, perdendo em números para os pedidos originados de pessoas físicas, que ficaram com 47\%. Quando se fala em pedido de patentes de modelo de utilidade, as ICTs foram responsáveis por apenas 3\% desses pedidos em 2017, ficando atrás das pessoas físicas (68\%), das empresas de médio e grande porte $(14 \%)$ e das empresas de pequeno porte (14\%). O baixo índice de depósitos de pedidos de registros de patentes advindos das ICTs contribui também para a afirmação das dificuldades enfrentadas pelas universidades na efetivação da interação com as empresas, uma vez que pouco se registra de propriedade intelectual, inviabilizando a posterior transferência dessa tecnologia para as empresas. 16 BRASIL. Secretaria de Assuntos Estratégicos da Presidência da República. Produtivismo includente: empreendedorismo vanguardista. Brasília: SAE/PR, 2015.

17 BOBBIO, Norberto. Da estrutura à função: novos estudos de teoria do Direito. Barueri: Manole, 2007. p. 6.
} 
Nesse sentido, Bobbio explorou e promoveu um Direito destinado a atender, cada vez mais, as difíceis e complexas necessidades de um Estado não mais regulador de todos os direitos e obrigações individuais e coletivas, mas obrigado a dar liberdade às relações contratuais privadas individuais e empresariais, perante uma estrutura jurídica estanque a se transformar para promover interesses gerais, voltados para o desenvolvimento da sociedade pensada coletivamente ${ }^{18}$.

A partir dessa perspectiva, cabe ao Estado instrumentalizar a estrutura jurídica com a função de conduzir o cidadão a praticar boas ações para com a sociedade. Nesse sentido, o pensamento de Bobbio vem ao encontro do objetivo geral proposto na presente pesquisa, consistente em contribuir para a consolidação do direito fundamental ao desenvolvimento por meio do aumento da interação entre universidade e empresa, para além da mera positivação, sendo necessárias políticas públicas que promovam tal interação.

Complementarmente, está o pensamento de Amartya Sen, para quem o papel do desenvolvimento analisado somente através de fatores como o crescimento do produto interno bruto, aumento de renda, industrialização, avanço tecnológico ou modernização social são insuficientes para a expansão das liberdades. Para o autor, o crescimento econômico não pode ser considerado fim em si mesmo, deve estar relacionado com a melhoria de vida dos indivíduos e com o fortalecimento das liberdades ${ }^{19}$.

Assim, o Marco Legal da Inovação tem importante papel na promoção da melhoria de vida dos indivíduos, pois estimula a conexão entre as pesquisas desenvolvidas na universidade e a transferência dessa tecnologia para o setor privado, permitindo com que a população tenha acesso às pesquisas desenvolvidas no meio acadêmico-científico.

Dessa forma, esse diploma legal modificou não apenas a Lei de Inovação, mas diversas legislações atinentes ao processo de otimização e valorização da inovação brasileira, como a Lei de Licitações, por exemplo. Essas alterações serão tratadas adiante, sob o olhar do aumento da interação entre universidade e empresa, como premissa para a consolidação do direito fundamental ao desenvolvimento.

\subsection{Marco Legal da Inovação e o aumento do incentivo à interação entre universidade e empresa}

Em 8 de janeiro de 2016, foi sancionada a Lei no 13.243, fruto do Projeto de Lei da Câmara - PLC $n^{\circ}$ $77 / 2015^{20}$, e, anteriormente, do Projeto de Lei - PL no 2.177/2011²1, que instituiu o chamado Marco Legal da Inovação no Brasil. Esse tópico dedica-se a analisar as principais mudanças trazidas por essa legislação na melhoria da interação entre a universidade e a empresa, comparando-o à Lei de Inovação.

$\mathrm{Na}$ redação original da Lei de Inovação, o conceito de ICT abrangia os entes da administração pública executores de atividades de pesquisa e inovação, como as universidades e institutos públicos de pesquisa. Porém, levando-se em consideração a abrangência do Sistema Nacional de Inovação (SNI) ${ }^{22}$, a Lei 13.243/16 modificou tal previsão legal e ampliou o conceito de ICT, passando-se a incluir as mais diversas instituições

\footnotetext{
BOBBIO, Norberto. Da estrutura à função: novos estudos de teoria do Direito. Barueri: Manole, 2007. p. 50.

SEN, Amartya. Desenvolvimento como liberdade. São Paulo: Companhia das Letras, 2000.

20 BRASIL. Senado Federal. Projeto de Lei da Câmara no 77/2015. Brasília: Senado Federal, 2015. Disponível em: <http://goo.gl/ EnXv0w>. Acesso em: 21 jul. 2018.

21 BRASIL. Câmara do Deputados. Projeto de Lei no 2.177/2011. Institui o Código Nacional de Ciência, Tecnologia e Inovação. Brasília, 2011. Disponível em: <http://goo.gl/xyejaA> Acesso em: 17 jul. 2018.

22 É preciso entender o significado de Sistema Nacional de Inovação para compreender o papel das universidades no desenvolvimento tecnológico de um país. O Sistema Nacional de Inovação compreende uma rede de instituições públicas e privadas e de mecanismos que produzem, disseminam e desenvolvem inovações tecnológicas em determinado país. Incluem-se nesse sistema: as universidades, o governo, as agências reguladoras e de fomento, as leis de inovação e de propriedade intelectual, as empresas públicas e privadas e seus laboratórios de pesquisa, as associações empresariais, os institutos de pesquisa, as escolas técnicas, dentre outros. PÓVOA, L.M.C. Patentes de universidades e institutos públicos de pesquisa e a transferência de tecnologia para empresas no Brasil. 2008. Tese (Doutorado em Economia) - Universidade Federal de Minas Gerais, Belo Horizonte, 2008.
} 
com diferentes personalidades jurídicas vinculadas à esfera pública e que também realizam atividades de PD\&I, assim como as instituições de direito privado sem fins lucrativos e algumas organizações sociais.

Nesse contexto, o Decreto $n^{\circ}$ 9.283, de 7 de fevereiro de 2018, que regulamentou o Marco Legal da Inovação, fez a diferenciação entre ICT pública e privada, de forma que a ICT pública é a integrante da administração pública direta ou indireta, incluídas as empresas públicas e as sociedades de economia mista. Já a ICT privada é constituída sob a forma de pessoa jurídica de direito privado sem fins lucrativos ${ }^{23}$.

Uma importante possibilidade de interação entre universidade e empresa prevista na Lei de Inovação consiste na possibilidade de compartilhamento de laboratórios, instrumentos, equipamentos, materiais e demais instalações das ICTs em atividades de incubação de empresas, além da permissão para utilização dessas instalações para a realização de atividades de PD\&I, que podem ser voltadas para um produto específico solicitado por determinada empresa.

$\mathrm{Na}$ redação original da Lei de Inovação estabeleceu-se que o estímulo para que ICTs engajem-se nas atividades de PD\&I é a possibilidade de remuneração para tanto. A Lei 13.243/2016 inovou no sentido de permitir que a contrapartida para compartilhamento e permissão de utilização de instalações de ICTs públicas seja financeira ou não financeira, revogando-se a expressão "remunerada" prevista na redação original. Isso significa que as ICTs podem receber como forma de contrapartida pelo compartilhamento dos laboratórios, por exemplo, o protótipo resultante do projeto desenvolvido ou a cotitularidade da tecnologia desenvolvida ${ }^{24}$.

Ademais, pairava a insegurança jurídica na forma de captação desses recursos pelas ICTs. Com o intuito de tentar conferir maior segurança a essas relações, em 2014, a Portaria MCTI no 251/2014 regulamentou a forma de recebimento de remuneração dos órgãos da administração pública por ente privado com relação à permissão de utilização de instalações de seus laboratórios e unidades de pesquisa, estipulando que seria por meio de Guia de Recolhimento da União - GRU. Porém, apesar da regra trazida pela Portaria Ministerial, as universidades não se sentiram estimuladas a praticar essa interação com o setor produtivo, uma vez que os recursos advindos de suas atividades de PD\&I acabavam não permanecendo em seus próprios orçamentos, mas sendo destinadas ao Tesouro Nacional ${ }^{25}$.

Para melhorar a gestão desses recursos, o Marco Legal da Inovação modificou tal entendimento e estabeleceu que os recursos financeiros de contrapartidas pelas parcerias com as ICTs poderão ser repassados pelas contratantes diretamente para as fundações de apoio, estabelecendo, assim, a possibilidade de os recursos advindos das atividades de PD\&I serem reaplicados na própria instituição, constituindo importante incentivo à interação entre universidade e empresa.

Em que pese ter ocorrido essa mudança positiva, ainda paira a insegurança jurídica com relação a captação por ICTs de recursos oriundos da prestação de serviços a empresas mediante fundações de apoio, uma vez que não houve alteração na redação dos parágrafos $2^{\circ}, 3^{\circ}$ e $4^{\circ}$ do artigo $8^{\circ}$ da Lei de Inovação, que regulamentam o recebimento de retribuição pecuniária por pesquisadores envolvidos nessas atividades.

Assim, permanecem os questionamentos das ICTs sobre como esses valores devem ser calculados, tanto em relação ao tempo de dedicação do pesquisador quanto o valor e a forma de recebimento dessa retribuição. Nesse sentido, a nova legislação continua propícia a subutilização do mecanismo de incentivo e ao envolvimento de pesquisadores públicos na prestação de serviços em atividades de PD\&I.

23 BRASIL. Decreto $n^{\circ}$ 9.283, de 7 de fevereiro de 2018. Regulamenta a Lei no 10.973, de 2 de dezembro de 2004, dentre outras. Diário Oficial da União, Brasilia, 2018. Disponível em: < http://www.planalto.gov.br/ccivil_03/_ato2004-2006/2004/lei/110.973. htm>. Acesso em: 21 de jul. 2018.

24 BARBOSA, Cynthia Mendonça; ARAÚJO, Elza Fernandes de. O novo marco legal da ciência, tecnologia e inovação e os seus principais enfoques. In: ESPINDOLA, Foued Salmen; PALUMA, Thiago. Boas práticas em gestão da inovação. Curitiba: Íthala, 2017. p. 23.

25 RAUEN, C. O novo marco legal da inovação no Brasil: o que muda na relação ICT-empresa? Radar 43, p.26, fev. 2016. 
Diante de tal lacuna, o Tribunal de Contas da União (TCU) vem consolidando seu entendimento sobre os temas mais relevantes que cercam essa matéria, como a impossibilidade do estabelecimento de remuneração de fundação de apoio fundada em taxa de administração, comissão, participação ou outra espécie de recompensa variável, que não traduza preço certo $^{26 ;}$ ilegalidade de contratação indireta de pessoal por fundação de apoio interposta para a execução de atividades inerentes ao plano de cargos e salários da ICT, por constituir fraude ao instituto do concurso público ${ }^{27}$ e a possibilidade de incorporação às IFES de bens adquiridos na execução de projetos ${ }^{28}$;

No que diz respeito à participação de pessoal docente e de técnicos administrativos, o TCU tem deliberado pela firme aplicação dos requisitos exigidos pela Lei 8.958/1994 (prazo determinado, fora da jornada de trabalho, excetuada a colaboração eventual, sem prejuízo de suas atribuições funcionais ${ }^{29}$. T TCU tem se posicionado pela exigência de projeto voltado para a pesquisa, ensino e desenvolvimento institucional, com prazo determinado ${ }^{30}$ e também pela irregularidade da subcontratação total do objeto de ajustes realizados pelas IFES com suas fundações de apoio por intermédio de dispensa de licitação, bem como pela subcontratação parcial que delegue a terceiros a execução do núcleo do objeto contratado, por constituir fraude ao regular processo licitatório ${ }^{31}$. Por fim, o TCU também entendeobrigatória a prestação de contas dos convênios regidos pela Lei ${ }^{\circ} 8958 / 1994^{32}$.

Outro importante instrumento de estímulo à interação universidade-empresa é a possibilidade de compartilhamento de laboratórios, equipamentos, instrumentos, materiais e demais instalações (art. $4^{\circ}$, I do Marco Legal da Inovação). A nova Lei modificou o destinatário desse compartilhamento de "microempresas e empresas de pequeno porte" para "ICT ou empresas", ampliando o público que pode ser beneficiado ${ }^{33}$.

O Marco Legal da Inovação, também, oficializou a modalidade de incubação de projetos tecnológicos, na qual as equipes das empresas ficam incubadas para desenvolverem seus projetos em constante interação com as equipes das universidades ou das demais espécies de $\mathrm{ICTs}^{34}$, criando importante instrumento para o fortalecimento da relação entre a empresa incubada e a ICT que a apoiou.

Destaca-se, também, dentre as principais alterações à Lei de Inovação, a oficialização de uma prática comum, que consiste na cessão ao parceiro privado dos direitos da propriedade intelectual das criações resultantes da parceria, transferindo-se a titularidade e os direitos de exploração econômica ao parceiro, como alternativa ao licenciamento (com ou sem exclusividade).

Nesse contexto, sobre o tema propriedade intelectual, o Decreto $n^{\circ} 9.283^{35}$ regulamenta algumas questões importantes, como: a previsão da titularidade da propriedade intelectual e a participação nos resultados da exploração das criações resultantes da parceria; a modalidade de reembolso de custos sem remuneração adicional, dentre outros ${ }^{36}$.

Outra importante alteração proposta pelo PLC 77/2015 foi a possibilidade de que alunos de curso técnico, graduação ou pós-graduação também pudessem desenvolver atividades de inovação nas ICTs a que se vinculam, podendo receber bolsa de estímulo à inovação. A Mensagem Presidencial no 8/2016 vetou tal

\footnotetext{
Acórdãos no 716/2016 - P, 1233/2006 - P, dentre outros;

Acórdãos no $3548 / 2006-1^{\text {a }} \mathrm{C}, 6 / 2007-\mathrm{P}$, dentre outros;

Acórdãos n 302/2006 - P, 966/2006 - P, dentre outros;

Acórdãos no 302/2006 - P, 2135/2006 - P, dentre outros;

Acórdãos n 2295/2006 - P - Relação 152/2006 GAB VC, 253/2007 - P Relação 9/2007 GAB GP, dentre outros;

Acórdãos no 2259/2007 - P Relação 41/2007 GAB GP, 1273/2006 - 2ª C, dentre outros;

Acórdãos no 1966/2006 - $1^{\mathrm{a}} \mathrm{C}, 1882 / 2007-\mathrm{P}$, dentre outros;

ARAÚJO, Nizete Lacerda et al. Marco legal da inovação: breves comentários. Rio de Janeiro: Lumen Juris, 2018. p. 143.

4 RAUEN, C. O novo marco legal da inovação no Brasil: o que muda na relação ICT-empresa? Radar 43, p. 26, fev. 2016.

35 BRASIL. Decreto n ${ }^{\circ}$ 9.283, de 7 de fevereiro de 2018. Regulamenta a Lei no 10.973, de 2 de dezembro de 2004, dentre outras. Diário Oficial da União, Brasília, 2018. Disponível em: < http://www.planalto.gov.br/ccivil_03/_ato2004-2006/2004/lei/110.973. htm>. Acesso em: 21 de jul. 2018.

36 ARAÚJO, Nizete Lacerda et al. Marco legal da inovação: breves comentários. Rio de Janeiro: Lumen Juris, 2018. p. 185.
} 
possibilidade, sob o argumento de que reduziriam as receitas tributárias da União, promovendo desequilíbrio fiscal ${ }^{37}$. Esse veto consolida o desestímulo ao engajamento de alunos de ICTs privadas em atividades de PD\&I, situação apartada do interesse público na consolidação do direito fundamental ao desenvolvimento.

No entanto, o $\int 4^{\circ}$ do art. 35 do Decreto $n^{\circ} 9.283$ voltou a regulamentar o assunto, ao estipular que o servidor público, militar, empregado de ICT pública e estudante de curso técnico, de graduação ou de pós-graduação, envolvidos na execução das atividades previstas no caput ${ }^{38}$ poderão receber bolsa de estímulo à inovação diretamente da ICT a que estiverem vinculados, de fundação de apoio ou de agência de fomento ${ }^{39}$.

Para gerir esse papel ativo das ICTs, a Lei de Inovação concebeu os NITs, com o objetivo geral de gestão da política de inovação e propriedade intelectual de ICTs, além da função de aproximação entre ICTs e empresas em atividades de PD\&I. Essas eram, basicamente, as suas atribuições na redação original da Lei de Inovação.

Adicionalmente, o Marco Legal da Inovação atribuiu novas funções e atividades de caráter estratégico, analítico e prospectivo aos NITs. Assim, ocorreu o fortalecimento do papel a ser desempenhado por esse núcleo dentro das ICTs. No entanto, o grande destaque no que se refere às modificações do papel dos NITs é a possibilidade de possuírem personalidade jurídica própria, inclusive, alterando a Lei no 8.958/1994, podendo assumir a personalidade jurídica de fundações de apoio.

Essa nova alternativa traz, dentre outras vantagens, a maior flexibilidade na gestão dos recursos financeiros dos NITs, inclusive com a possibilidade de constituírem orçamentos independentes das ICTs, e a maior celeridade e possibilidade de atração de perfis e contratação de funcionários com maior capital intelectual para gerir as competências legais, no que tange à política de inovação das ICTs.

Portanto, diversas foram as modificações trazidas pelo Marco Legal da Inovação, que, em certa medida, contribuíram para o aumento da interação entre a universidade e a empresa. No próximo tópico, analisar-se-á como esse aumento de interação contribui para a consolidação do direito fundamental ao desenvolvimento.

\section{Contribuições do aumento da interação entre universidade e empresa para a consolidação do direito fundamental ao desenvolvimento}

Esse tópico analisará, primeiramente, a natureza jurídica do direito fundamental ao desenvolvimento, com base na Teoria dos Direitos Fundamentais e na Constituição Federal. Adiante, abordar-se-á um princípio em específico, positivado no ordenamento jurídico pelo Marco Legal da Inovação, no artigo $1^{\circ}$, parágrafo único, inciso I, que pretende a "promoção das atividades científicas e tecnológicas como estratégicas para o desenvolvimento econômico e social" ${ }^{40}$. Por fim, verificar-se-á como o aumento da interação entre universidade e empresa pode contribuir de fato para a consolidação do direito fundamental ao desenvolvi-

\footnotetext{
37 BRASIL. Palácio do Planalto. Mensagem Presidencial no 8, de 11 de janeiro de 2016. Diário Oficial da República Federativa do Brasil, Brasília: Palácio do Planalto, 2016. Disponível em: <http://goo.gl/bDLeXz>.

38 Art. 35. O acordo de parceria para pesquisa, desenvolvimento e inovação é o instrumento jurídico celebrado por ICT com instituições públicas ou privadas para realização de atividades conjuntas de pesquisa científica e tecnológica e de desenvolvimento de tecnologia, produto, serviço ou processo, sem transferência de recursos financeiros públicos para o parceiro privado, observado o disposto no art. $9^{\circ}$ da Lei n ${ }^{\circ} 10.973$, de 2004.

39 BRASIL. Decreto $n^{\circ} 9.283$, de 7 de fevereiro de 2018. Regulamenta a Lei $n^{\circ} 10.973$, de 2 de dezembro de 2004, a Lei $n^{\circ}$ 13.243, de 11 de janeiro de 2016, dentre outros. Diário Oficial da União, Brasília, 2018. Disponível em: <http:/ /www.planalto.gov.br/ ccivil_03/_ato2004-2006/2004/lei/110.973.htm>. Acesso em: 21 jul. 2018.

40 BRASIL. Lei n. ${ }^{\circ} 13.243$, de 11 de janeiro de 2016. Dispõe sobre estímulos ao desenvolvimento científico, à pesquisa, à capacitação científica e tecnológica e à inovação e altera a Lei n ${ }^{\circ}$ 10.973, de 2 de dezembro de 2004, dentre outras. Diário Oficial da República Federativa do Brasil, Brasília, DF, 12 jan. 2016. Disponível em: < http://www.planalto.gov.br/ccivil_03/_ato2015-2018/2016/lei/ 113243.htm> Acesso em: 22 jun. 2018.
} 
mento, com base na necessidade do aprimoramento das políticas públicas desempenhadas pelos NITs.

\subsection{Do direito ao desenvolvimento e da sua natureza jurídica}

Após a Segunda Guerra Mundial ocorreu uma nova geração de constituições oriundas dos países que estavam passando pelo processo de reconstrução, assim como dos novos Estados que conseguiram sua independência ${ }^{41}$. Tais constituições reposicionaram o tema do desenvolvimento para além da busca da felicidade individual, abordando a nova concepção de justiça social, impondo a transformação da realidade para um determinado fim constitucionalmente estabelecido.

Nesse sentido, a constituição brasileira de 1988 é considerada um exemplo de reencontro entre o texto constitucional e a questão do desenvolvimento. De uma maneira geral, se as constituições do século XIX se destacavam pela omissão do termo desenvolvimento, as constituições do século XX colocam o desenvolvimento como objetivo do Estado de bem-estar social.

No preâmbulo da constituição brasileira, o desenvolvimento é posto como um fim ao qual o Estado Democrático deve se dedicar. No corpo da lei maior, a primeira referência do termo desenvolvimento é na qualidade de um dos objetivos fundamentais da República Federativa do Brasil, conforme consta do seu art. $3^{\circ}$. Inicialmente, no âmbito da Constituição brasileira de 1988, pode-se constatar alguma dificuldade em perceber, imediatamente, a existência de um direito fundamental ao desenvolvimento, na medida em que figura como um dos fundamentos da República Federativa do Brasil, não constando no rol dos direitos individuais do art. $5^{\circ}$.

No entanto, no direito internacional, encontramos a Resolução no 41/128 da Assembleia Geral das Nações Unidas, de 4 de dezembro de 1986, que dispõe sobre o direito ao desenvolvimento como um direito humano inalienável, em virtude do qual todas as pessoas estão habilitadas a participar do desenvolvimento econômico, social, cultural e político, no qual tanto os direitos humanos quanto as liberdades fundamentais possam ser plenamente realizados ${ }^{42}$.

Ademais, é conferido ao Estado papel de protagonista da efetivação dessa categoria de direito, tal como pode ser percebido pelo artigo 2.3 da referida declaração, que disciplina o direito e o dever do Estado de formular políticas nacionais adequadas para o desenvolvimento, que visem ao constante aprimoramento do bem-estar de toda a população e de todos os indivíduos, com base no desenvolvimento e na distribuição equitativa dos benefícios daí resultantes.

Ainda assim, persiste apreciar se, na ordem constitucional pátria, é possível afirmar a existência de um direito fundamental ao desenvolvimento, tal como previsto na Declaração das Nações Unidas sobre o Desenvolvimento. Retomando os conceitos de direitos fundamentais, Robert Alexy defende suas acepções, uma no sentido formal e outra no sentido material. Em sentido formal, direitos fundamentais "são posições que são tão importantes que a decisão sobre garanti-las ou não garanti-las não pode ser simplesmente deixada para a maioria parlamentar simples" ${ }^{\prime 3}$.

Sob o ponto de vista substancial, a noção de direitos fundamentais é determinada pelo conceito de dignidade da pessoa humana. Assim, de um lado, existe a ideia de direitos fundamentais prévios ao Estado, que defendem os indivíduos da atuação deste, e, de outro lado, a ideia de direitos fundamentais que existem na medida em que os cidadãos estejam organizados em sociedade, permitindo a proteção de determinados valores socialmente relevantes ${ }^{44}$.

41 São exemplos a Constituição indiana de 1950, a Lei Fundamental alemã de 1949, a constituição portuguesa de 1975, a constituição brasileira de 1988 e a constituição sul-africana de 1993.

42 PALUMA, Thiago. Propriedade Intelectual e direito ao desenvolvimento. São Paulo: Pillares, 2017. p. 86.

43 ALEXY, Robert. Teoria dos direitos fundamentais. 2. ed. São Paulo: Malheiros, 2017. p. 446.

44 Na constituição federal brasileira, o Estado é chamado a desenvolver o papel de propulsor do desenvolvimento. 
Considerando-se que o direito fundamental ao desenvolvimento não está expressamente elencado no rol de direitos fundamentais da constituição brasileira, questiona-se a possibilidade de se extrair dos fundamentos do Estado um direito fundamental ao desenvolvimento. Sobre a existência de direitos fundamentais ausentes do rol do art. $5^{\circ}$ da Constituição brasileira, Sarlet sustenta a possibilidade de ocorrência tanto escritos, positivados na Constituição ou em tratados internacionais, quanto não escritos, deduzidos com base nos princípios fundamentais ${ }^{45}$.

Sustenta-se, no presente artigo, a existência de um direito ao desenvolvimento decorrente dos princípios da Constituição e de documentos internacionais de Direitos Humanos, ou seja, de um direito fundamental que não integra o rol, formal, de direitos fundamentais do art. $5^{\circ}$, encontrando tal status por força do disposto no $₫ 2^{\circ}$ do mesmo artigo da Constituição de 1988. Ao considerar-se que o desenvolvimento nacional é um fundamento da República Federativa do Brasil, há uma obrigação para o Estado de tomar as medidas necessárias para promover o desenvolvimento do País e, conforme Alexy, a todo dever corresponde um direito de alguém a algo ${ }^{46}$. Assim, se ao Estado é incumbido o dever de promover o desenvolvimento, ao sujeito é conferido o direito a esse algo, nesse caso, ao desenvolvimento.

Dessa maneira, no caso da Constituição Federal, o direito ao desenvolvimento encontra-se na categoria dos direitos fundamentais decorrentes, por força do já citado $₫ 2^{\circ}$ do art. $5^{\circ}$ da Constituição da República ${ }^{47}$ e da Declaração das Nações Unidas sobre o Direito ao Desenvolvimento. Ademais, entre as possíveis classificações e categorizações a que o direito ao desenvolvimento pode se sujeitar, merece referência a classificação quanto às dimensões dos direitos. Trata-se de um direito fundamental de terceira dimensão ${ }^{48}$, que se destaca por possuir uma titularidade difusa, de natureza coletiva. Em direitos dessa dimensão, o Estado possui um importante papel para sua efetivação e expansão.

\subsubsection{A inserção do princípio integrador entre desenvolvimento científico, tecnológico, econô- mico e social pelo Marco Legal da Inovação e a sua compatibilidade com a teoria do de- senvolvimento como liberdade}

O Marco Legal da Inovação alterou o artigo $1^{\circ}$ da Lei de Inovação, ao inserir o parágrafo único, com a inserção de quatorze princípios. O primeiro deles compõe o objeto de pesquisa do presente estudo, e será tratado a seguir:

Art. 1o Esta Lei estabelece medidas de incentivo à inovação e à pesquisa científica e tecnológica no ambiente produtivo, com vistas à capacitação tecnológica, ao alcance da autonomia tecnológica e ao desenvolvimento do sistema produtivo nacional e regional do País, nos termos dos arts. 23, 24, 167, 200, 213, 218, 219 e 219-A da Constituição Federal. (Redação pela Lei no 13.243, de 2016).

Parágrafo único. As medidas às quais se refere o caput deverão observar os seguintes princípios: (Incluído pela Lei no 13.243, de 2016).

I - promoção das atividades científicas e tecnológicas como estratégicas para o desenvolvimento

\footnotetext{
45 SARLET, Ingo Wolfgang. A eficácia dos direitos fundamentais. 8. ed. Porto Alegre: Livraria do Advogado, 2007. p. 57.

46 ALEXY, Robert. Teoria dos direitos fundamentais. 2. ed. São Paulo: Malheiros, 2017.

47 Art. $5^{\circ}[\ldots] \S 2^{\circ}$ - Os direitos e garantias expressos nesta Constituição não excluem outros decorrentes do regime e dos princípios por ela adotados, ou dos tratados internacionais em que a República Federativa do Brasil seja parte.

48 De acordo com Ingo Sarlet, "verifica-se crescente convergência de opiniões no que concerne à idéia que norteia a concepção das três (ou quatro, se assim preferirmos) dimensões dos direitos fundamentais, no sentido de que estes, tendo tido sua trajetória existencial inaugurada com o reconhecimento formal nas primeiras Constituições escritas dos clássicos direitos de matriz liberalburguesa, se encontram em constante processo de transformação, culminando com a recepção, nos catálogos constitucionais e na seara do Direito Internacional, de múltiplas e diferenciadas posições jurídicas, cujo conteúdo é tão variável quanto as transformações ocorridas na realidade social, política, cultural e econômica ao longo dos tempos. Assim sendo, a teoria dimensional dos direitos fundamentais não aponta, tão-somente, para o caráter cumulativo do processo evolutivo e para a natureza complementar de todos os direitos fundamentais, mas afirma, para além disso, sua unidade e indivisibilidade no contexto do direito constitucional interno e, de modo especial, na esfera do moderno "Direito Internacional dos Direitos Humanos." SARLET, Ingo Wolfgang. A eficácia dos direitos fundamentais. 8. ed. Porto Alegre: Livraria do Advogado, 2007. p. 55.
} 
econômico e social; (Incluído pela Lei no 13.243, de 2016).

Essa modificação positiva no ordenamento jurídico brasileiro um importante esclarecimento sobre as intenções integrativas do desenvolvimento. Isso porque, de forma clássica, a Economia era a ciência que se preocupava com a Teoria do Desenvolvimento. Nesse cenário, pensava-se o desenvolvimento econômico de forma apartada do desenvolvimento social, científico e tecnológico.

Assim, Paluma ${ }^{49}$ discorre sobre a diferenciação entre desenvolvimento e crescimento. O desenvolvimento consiste na relação mútua entre fatores sociais e econômicos, que pode ser, com base no referencial teórico eleito, estendido a outras hipóteses, como as liberdades individuais e o exercício pleno da democracia. Em contrapartida, o crescimento consiste na análise fria dos dados utilizados. Nesse contexto, o aumento do Produto Interno Bruto - PIB de determinado país refere-se ao crescimento econômico, sem nenhuma preocupação com a transferência de riquezas para as classes menos favorecidas ou com a melhoria da situação social e tecnológica de determinado país ou região.

Essa visão mais ampla de desenvolvimento encontra-se na obra Desenvolvimento como Liberdade de Amartya Sen. Para o referido autor, o desenvolvimento pressupõe a remoção das principais fontes de privação de liberdade, como a pobreza, a tirania, a carência de oportunidades econômicas, a negligência dos Estados repressivos e a destituição social sistemática ${ }^{50}$.

Nesse sentido, para que ocorra o desenvolvimento não basta a obtenção de um determinado nível econômico ou social. É imprescindível que o Direito atue como regulador da liberdade, a partir do momento que o desenvolvimento é encarado como um direito fundamental inalienável. Sen destaca-se por indicar o ser humano como o elemento central na busca pelo desenvolvimento, não podendo ser aceitável a privação de sua liberdade em busca de desenvolvimento econômico.

Na abordagem de Sen, a expansão da liberdade é considerada o principal fim e também o principal meio para o desenvolvimento. Para a melhor compreensão da sua abordagem, é preciso analisar as liberdades instrumentais ou liberdades meio. São elas: as liberdades políticas; as oportunidades sociais; as garantias de transparência; as facilidades econômicas e a segurança protetora ${ }^{51}$.

As liberdades políticas referem-se ao direito que os cidadãos possuem de escolher seus governantes, fiscalizar e criticar as autoridades públicas e a liberdade de expressão. As oportunidades sociais são relacionadas com o oferecimento de saúde, educação, dentre outros, para a garantia de uma vida melhor da sociedade. As garantias de transparência visam proteger contra a corrupção e transações ilícitas. As facilidades econômicas dizem respeito à disponibilidade e à utilização dos recursos econômicos, preços, condições e bom funcionamento dos mercados. Por fim, a segurança protetora compreende a rede de segurança social, responsável por evitar que os indivíduos se submetam à miséria, fome, e demais situações degradantes.

Assim, para Sen, a utilidade da riqueza não está nela mesma, e sim nas possibilidades que ela permite aos indivíduos realizarem. Por isso, medidas como o PIB não podem ser consideradas isoladamente, e sim dentro de um contexto de expansão das liberdades individuais. ${ }^{52} \mathrm{~A}$ liberdade dos indivíduos, nesse contexto, é elemento constitutivo fundamental do processo de desenvolvimento. Ainda, essas liberdades podem ser aumentadas por meio de políticas públicas e aperfeiçoadas por meio das capacidades participativas da população.

Nesse cenário, enquanto o desenvolvimento é a expansão de liberdades individuais, a pobreza é a privação das capacidades básicas. Ademais, para Sen, a Economia falha ao centrar na utilidade e deixar de lado o valor central da própria liberdade, enxergando uma visão muito restrita de mercados. Assim, o crescimento

49 PALUMA, Thiago. Propriedade intelectual e direito ao desenvolvimento. São Paulo: Pillares, 2017. p. 93.

$50 \quad$ SEN, Amartya. Desenvolvimento como liberdade. São Paulo: Companhia das Letras, 2000. p. 58.

1 SEN, Amartya. Desenvolvimento como liberdade. São Paulo: Companhia das Letras, 2000. p. 58-61.

52 SEN, Amartya. Desenvolvimento como liberdade. São Paulo: Companhia das Letras, 2000. p. 29. 
econômico deve ser avaliado com base na expansão de serviços sociais que esse crescimento pode propiciar, e não apenas com relação ao acréscimo de renda privada ${ }^{53}$.

Assim, a inserção do indivíduo na sociedade com a garantia das liberdades pessoais requer um comprometimento social. Nas palavras de Sen:

[...] Como pessoas que vivem — em um sentido amplo — juntas, não podemos escapar à noção de que os acontecimentos terríveis que vemos à nossa volta são essencialmente problemas nossos. Eles são responsabilidade nossa — independentemente de serem ou não de mais alguém ${ }^{54}$.

Nesse sentido integrativo entre desenvolvimento científico, tecnológico, econômico e social, destaca-se o pensamento de Silva ${ }^{55}$ e Segala e Gregori ${ }^{56}$, em que se ressalta a importância do desenvolvimento da propriedade intelectual (os NITs, nesse contexto, possuem a função de gerir a propriedade intelectual na conexão da universidade com as empresas) como meio para o fim primordial do desenvolvimento socioeconômico.

Ademais, Varella ${ }^{57}$ traz uma perspectiva que comporta duas faces da proteção da propriedade intelectual. A primeira é técnica, voltada para o cumprimento de acordos internacionais, como o TRIPS ${ }^{58}$. A segunda é política, voltada para o cumprimento da função social da propriedade, representada pela escolha de quais setores estimular. Ademais, para o referido autor, é por meio do equilíbrio dessas duas faces da propriedade intelectual que se pode pensar esse sistema de proteção como propulsor do desenvolvimento nacional.

No mesmo sentido, Benetti ${ }^{59}$ afirma que a proteção do desenvolvimento científico e tecnológico e sua transformação em inovação é o ponto de partida para alcançar o desenvolvimento científico e tecnológico do país.

Portanto, a Teoria do Desenvolvimento como liberdade de Amartya Sen guarda total compatibilidade com o princípio inserido no Marco Legal da Inovação, que pretende o desenvolvimento científico e tecnológico como propulsor do desenvolvimento econômico e social, tendo em vista que não se pode conceber o desenvolvimento econômico de maneira apartada do desenvolvimento social, tecnológico e científico, quando se pensa o desenvolvimento como um direito fundamental.

\subsection{Contribuições do aumento da interação entre universidade e empresa para a consolidação do direito fundamental ao desenvolvimento}

A Lei de Inovação determinou a política pública de instituição de NITs em ICTs, para a gestão da política de inovação, propriedade intelectual e transferência de tecnologia. O Marco Legal da Inovação ofereceu contribuições para o aumento da interação entre universidade e empresa. Nesse sentido, a Lei de Inovação, o Marco Legal da Inovação, o Decreto no 9283/2018, a Emenda Constitucional no 88/2015 e até mesmo a

53 SEN, Amartya. Desenvolvimento como liberdade. São Paulo: Companhia das Letras, 2000. p. 68-69.

54 SEN, Amartya. Desenvolvimento como liberdade. São Paulo: Companhia das Letras, 2000. p. 359.

55 SILVA, Tatianna Mello Pereira da. Acordo TRIPS: one-size-fits-all?. Revista de Direito Internacional, Brasília, v. 10, n. 1, p. $69,2013$. Disponível em: < https://www.publicacoesacademicas.uniceub.br/rdi/article/view/1987> Acesso em: 25 set. 2018.

56 SEGALA, Michele M.; GREGORI, Isabel Christine S. de. Os reflexos da proteção internacional da propriedade intelectual para o desenvolvimento interno: uma análise sobre o sistema patentário brasileiro e a transferência de tecnologia. Revista de Direito Internacional. Disponível em: <https://www.publicacoesacademicas.uniceub.br/rdi/article/view/4678> Acesso em: 24 set. 2018.

57 VARELLA, Marcelo Dias. Políticas públicas para propriedade intelectual no Brasil. In: (Org.). Propriedade intelectual e desenvolvimento. São Paulo: Lex, 2005. p. 189.

58 O TRIPS - Acordo Relacionado aos Direitos de Propriedade Intelectual - consiste em um acordo que teve início em meados de 1986, por insistência dos Estados Unidos e de mais alguns países desenvolvidos. Assim, as discussões sobre os direitos de propriedade intelectual foram levadas para o Gatt - Acordo Geral de Tarifas e Comércio. Durantre a última rodada de tratativas, que ocorreu no Uruguai, em 1994, criou-se a OMC - Organização Mundial do Comércio, e um anexo do próprio ato constitutivo dessa organização criou o TRIPS. BARBOSA, Denis Borges. TRIPS e a experiência brasileira. In: VARELLA, Marcelo Dias (Org.). Propriedade intelectual e desenvolvimento. São Paulo: Lex, 2005. p. 135.

59 BENET'TI, Daniela Vanila Nakalski. Proteção às patentes de medicamentos e comércio internacional. In: BARRAL, Welber; PIMENTEL, Luiz Otávio (Org.). Propriedade intelectual e desenvolvimento. Florianópolis: Fundação Boiteux, 2006. p. 346. 
Declaração sobre o Direito ao Desenvolvimento, adotada pela Resolução no 41/128 da Assembleia Geral das Nações Unidas, criam uma teia de valores a serem observados, que em conjunto positivam o direito fundamental ao desenvolvimento na ordem jurídica brasileira.

No entanto, observou-se que a simples positivação desse direito não é garantia de sua consolidação. Para tanto, a legislação vigente trouxe instrumentos que visam criar um ambiente propício para a interação entre universidade e empresa, sendo que em geral dependem da atuação do Estado e de políticas públicas que permitam a implementação desses instrumentos. Nesse contexto, Ruas ${ }^{60}$, em face da variedade de teorias e conceitos sobre Políticas Públicas, enfoca, primeiramente, a diferenciação social das sociedades modernas, nas quais existe a possibilidade de conflitos sociais, uma vez que convivem diferentes valores e interesses.

Dessa forma, para a resolução desses conflitos, por meio da coerção, utiliza-se a política. A política, no entendimento de Ruas ${ }^{61}$, consiste em um conjunto de procedimentos que expressam relações de poder e que se destinam à resolução pacífica de conflitos quanto a bens públicos. Já as políticas públicas compreendem um conjunto de decisões e ações relativas à alocação imperativa de valores.

As políticas públicas requerem diversas ações estrategicamente selecionadas para implementar decisões tomadas. Nesse sentido, as políticas públicas representam os instrumentos de ação dos governos, substituindo governos por leis — government by Law — pelos governos por políticas — government by policies. A fonte de justificação das políticas públicas é o Estado social, marcado pela obrigação de implementação dos direitos fundamentais positivos, como o direito fundamental ao desenvolvimento, que exige uma prestação positiva do Poder Público ${ }^{62}$. No mesmo sentido, está o pensamento de Bobbio ${ }^{63}$, colocando em evidência a função promocional do Direito.

É preciso estabelecer uma diferenciação: a política não é uma norma e nem um ato jurídico, no entanto, as normas e atos jurídicos compõem a política ${ }^{64}$. Segundo Fábio Konder Comparato, as políticas públicas constituem programas de ação do governo ${ }^{65}$. O referido autor concorda com Dworkin, para quem a política, quando contraposta à noção de princípio, designa aquela espécie de padrão de conduta que resulta em uma meta a alcançar, uma melhoria das condições econômicas, políticas ou sociais de determinada sociedade. Nas palavras de Dworkin:

Os argumentos de princípio se propõem a estabelecer um direito individual; os argumentos políticos se propõem a estabelecer um objetivo coletivo. Os princípios são proposições que descrevem direitos; as políticas são proposições que descrevem objetivos. ${ }^{66}$

O estudo das políticas públicas no Brasil está conectado à evolução sociológica do Direito e à consolidação do Estado democrático de direito — o Estado constitucional pautado pela defesa dos direitos de liberdade e pela implementação dos direitos sociais. No Estado constitucional, a função fundamental do Estado é a concretização dos direitos fundamentais, por meio de políticas públicas criadas no seio do Poder Legislativo ou pela própria Administração ${ }^{67}$, políticas formuladas por intermédio de intelecção sociológico-política.

\footnotetext{
${ }^{60}$ RUAS, Maria das Graças. Análise de políticas públicas: conceitos básicos. In: RUAS, Maria das Graças; CARVALHO, Maria Izabel Valladão de. (Org.). O estudo da política. Brasília: Paralelo 15, 1998. p. 231-260.

${ }^{61}$ RUAS, Maria das Graças. Análise de políticas públicas: conceitos básicos. In: RUAS, Maria das Graças; CARVALHO, Maria Izabel Valladão de. (Org.). O estudo da política. Brasília: Paralelo 15, 1998. p. 231.

${ }^{62}$ BUCCI, Maria Paula Dallari. As políticas públicas e o Direito Administrativo. Revista Trimestral de Direito Público, São Paulo, n. 13, p. 135, 1996.

${ }_{63}$ BOBBIO, Norberto. Da estrutura à função: novos estudos de teoria do Direito. Barueri: Manole, 2007.

64 COMPARATO, Fábio Konder. Ensaio sobre o juízo de constitucionalidade de políticas públicas. Revista dos Tribunais, São Paulo, ano 86, n. 737 , p. 18 , mar. 1997.

65 COMPARATO, Fábio Konder. Ensaio sobre o juízo de constitucionalidade de políticas públicas. Revista dos Tribunais, São Paulo, ano 86 , n. 737 , p. 18 , mar. 1997.

66 DWORKIN, Ronald. Levando os direitos a sério. Tradução Nelson Boeira. São Paulo: Martins Fontes, 2002. p. 134.

67 A Lei de Inovação é o principal exemplo, aqui, de legislação que estabeleceu uma política pública. Nesse sentido constata Bucci, que a exteriorização das políticas públicas se afasta de um padrão uniforme e claramente apreensível pelo ordenamento jurídico. BUCCI, Maria Paula Dallari. Políticas públicas e direito administrativo. Revista de Informação Legislativa, Brasília, ano 34, n. 133, p. 257, jan/mar. 1997.
} 
A política pública não é um tema ontologicamente jurídico, sendo originária da ciência política e, sobretudo, da sociologia. $\mathrm{O}$ interesse sociojurídico pelas políticas públicas vem crescendo em simetria com o crescimento do Poder Executivo, fenômeno próprio do Estado social ${ }^{68}$. As políticas públicas exigem um modo de agir do Estado nas funções dos agentes públicos e privados para a realização de certos fins.

Comparato $^{69}$ observa que ocorre um processo de substituição da lei pela política pública, mantendo-se a mesma separação entre a declaração, a execução e o controle. Assim, parece haver uma paulatina substituição da função das leis (sentido omissivo), pela função das políticas (comissivo). Nota-se que a noção de políticas públicas como a coordenação dos meios à disposição do Estado, harmonizando as atividades estatais e privadas para a realização de objetivos socialmente (ou economicamente) relevantes e politicamente determinados ${ }^{70}$ constitui, atualmente, o principal meio de consolidação dos direitos fundamentais.

Assim, os Núcleos de Inovação Tecnológica - NITs evoluem na sua forma de atuação como políticas públicas. Prova disso é a análise da evolução histórica de aprimoramento da legislação desenvolvida no tópico anterior. No entanto, ainda há muito a ser feito. Principalmente no que tange à necessidade de democratização dos espaços dos NITs, no sentido inverso: as empresas precisam demandar as universidades para o desenvolvimento de tecnologias específicas necessárias à sociedade.

Hoje, como abordado, as pesquisas são desenvolvidas dentro das universidades de maneira ainda muito desconectada do setor produtivo, ocorrem muitas vezes por afinidade de determinado professor pesquisador a certo objeto de pesquisa, sem que se observem as reais necessidades da sociedade. Assim, existe a necessidade de abertura dos espaços dos NITs para o setor produtivo, para que estes possam atuar na intermediação de conexão entre a demanda da sociedade e a demanda dos pesquisadores dentro das universidades, como forma de contribuir para a efetivação do direito fundamental ao desenvolvimento.

Esse caminho inverso pode ser efetivado por meio de editais de fomento, nos quais a administração pública ofereça benefícios tanto para as ICTs quanto para as empresas desenvolverem parcerias voltadas para a PD\&I. Uma interessante política pública de fomento, relacionada à CT\&I, é a da Financiadora de Inovação e Pesquisa -Finep, vinculada ao Ministério da Ciência Tecnologia, Inovações e Comunicações - MCTIC, intitulada de Finep Startup - Programa de Investimento em Startups Inovadoras (Rodada I e II), que utiliza os novos meios de fomento para a CT\&I, como a participação estatal como acionista minoritário na empresa/ startup. No entanto, esse edital destina-se, apenas, às empresas, e não se preocupou em fazer a conexão com as pesquisas dentro das universidades.

É importante ressaltar que já existem tímidos incentivos fiscais às empresas que invistam em PD\&I. É o caso da Lei de Informática (Lei $n^{\circ} 8.248 / 91$ ), que busca alterar a competitividade das empresas por meio da redução do Imposto sobre Produtos Industrializados (IPI) e a Lei do Bem (Lei no 11.196/2005) que permite a dedução direta dos dispêndios em PD\&I do lucro das firmas, alterando o custo de uso do capital destinado a esse investimento ${ }^{71}$.

Ademais, Pedro Marcos Nunes Barbosa ${ }^{72}$ atenta para a necessidade do poder público investir em CT\&I para mudar o seu quadro de dependência tecnológica externa, em detrimento de contar com componentes

\footnotetext{
${ }_{68}$ Fábio Konder Comparato ensina que o autor pioneiro nesta reclassificação das funções do Estado foi Karl Loewenstein, pregando a substituição da lei pela política pública. COMPARATO, Fábio Konder. Ensaio sobre o juízo de constitucionalidade de políticas públicas. Revista dos Tribunais, São Paulo, ano 86, n. 737, p. 17, mar. 1997.

69 COMPARATO, Fábio Konder. Ensaio sobre o juízo de constitucionalidade de políticas públicas. Revista dos Tribunais, São Paulo, ano 86, n. 737, p. 18, mar. 1997.

70 BUCCI, Maria Paula Dallari. Políticas públicas e direito administrativo. Revista de Informação Legislativa, Brasília, ano 34, n. 133, p. 91, jan/mar. 1997.

71 KANNEBLEY JÚNIOR, Sérgio; PORTO, Geciane Silveira. Incentivos fiscais à pesquisa, desenvolvimento e inovação no Brasil: uma avaliação das políticas recentes. Disponível em: <https://www.innovationpolicyplatform.org/system/files/Incentivos\%20Fiscais. pdf> Acesso em: 24 set. 2018.

72 BARBOSA, Pedro Marques Nunes. Ano eleitoral e políticas públicas de propriedade intelectual. 2018. Disponível em: < https://www.migalhas.com.br/dePeso/16,MI273534,41046-Ano+eleitoral+e+politicas+publicas+de+propriedade+intelectual> Acesso em: 25 set. 2018.
} 
puramente aleatórios para se desenvolver. Segundo o IPEA ${ }^{73}$, por exemplo, em 2015 o Governo Federal empenhou R $\$ 37$ bilhões com ciência e tecnologia, o que significaria apenas $0,63 \%$ do PIB. Nesse sentido, considera-se baixíssimo o grau de investimento federal em PD\&I.

Por fim, Gonçal Mayos Solsona evidencia a necessidade do pensar pós-disciplinar, ou seja, avançar por um horizonte de potencialização do aprendizado, para permitir avanços no conhecimento, uma vez que os problemas inseridos na sociedade contemporânea são complexos e globais, devendo ser encarados cada vez mais de maneira pós-disciplinar. Nesse sentido, as fronteiras disciplinares criadas ao longo dos séculos XIX e XX não devem constituir-se como limitadoras do pensamento jurídico ${ }^{74}$. Ao contrário, elas devem funcionar como pontes de aprendizado, sendo que o Direito muitas das vezes precisa de políticas públicas para se efetivar.

Conclui-se, assim, que as políticas públicas desempenhadas pelos NITs nas ICTs são hoje um importante meio para a consolidação do direito fundamental ao desenvolvimento, no entanto, elas precisam ser aprimoradas e ampliadas. Ademais, a simples positivação das melhorias de interação entre universidade e empresa, apesar de não ser garantia para que a interação ocorra de fato, é um grande ponto de partida para que surjam as mudanças desejadas nesse cenário, sendo necessárias, ainda, funções promocionais por parte do Estado.

\section{Considerações finais}

As alterações promovidas pelo Marco Legal da Inovação foram benéficas ao aumento da interação entre universidade e empresa, uma vez que buscaram reduzir a insegurança jurídica e fortalecer as possibilidades vigentes, enfatizando as ferramentas de estímulo ao aumento da participação empresarial no processo inovativo, que permanece em patamar aquém do esperado.

Ademais, é possível conceber o direito ao desenvolvimento como um direito fundamental no ordenamento jurídico brasileiro, e o Marco Legal da Inovação positiva um importante princípio que explicita as intenções integrativas entre desenvolvimento científico, tecnológico, social e econômico, mostrando-se compatível com a formulação do conceito de desenvolvimento de Amartya Sen.

A mera positivação do direito fundamental ao desenvolvimento é insuficiente por si só, do ponto de vista prático, para sua consolidação, carecendo de efetivas políticas públicas voltadas para esse fim. Esse é o papel a ser desempenhado pelos NITs, e o aprimoramento da interação entre universidade e empresa pelo Marco Legal da Inovação é a prova de que o direito fundamental ao desenvolvimento caminha, mesmo que lentamente, para a sua consolidação.

Nesse sentido, no Brasil, desabrocha lentamente um movimento de otimização das leis relacionadas à inovação, para inserir nelas políticas públicas capazes de aumentar a interação entre as universidades e as empresas, uma vez que as leis possuem um sentido omissivo e as políticas públicas possuem um sentido comissivo. Em outras palavras, ocorre uma reclassificação das funções do Estado, decorrente da própria natureza do Estado social, que consiste em um agir do Estado, para a efetivação dos direitos de liberdade e a implementação dos direitos sociais.

Assim, o próximo passo consiste em efetivar políticas públicas dentro dos espaços conferidos aos NITs, no sentido de conectar as reais necessidades da sociedade, refletidas nas demandas do setor produtivo, com as pesquisas desenvolvidas dentro das universidades. Para tanto, é imprescindível que se aumente o investi-

\footnotetext{
O dado está no artigo "Dispêndios do Governo Federal em C\&T e P\&D: esforços e perspectivas recentes", que faz parte da $48^{a}$ edição do Boletim Radar, publicado pelo Ipea. Disponível em: <http://www.ipea.gov.br/radar/temas/ciencia-tecnologia-einovacao/627-dispendios-do-governo-federal-em-c-t-e-p-d-esforcos-e-perspectivas-recentes> Acesso em: 25 set. de 2018.

74 SOLSONA, Gonçal Mayos. Empoderamiento Y desarrollo humano: actuar local y pensar postdisciplinarmente. In: DÍAZ, Yanko Moyano et al. Postdisciplinariedad y desarrollo bumano: entre pensamiento y política. Barcelona: Linkgua, 2014. p. 193.
} 
mento em Ciência e Tecnologia, por meio de investimentos diretos e de políticas públicas indutivas.

Em última análise, o aumento da interação entre universidade e empresa contribui, significativamente, para a consolidação do direito fundamental ao desenvolvimento, tendo em vista que os NITs nasceram como políticas públicas cuja finalidade é justamente desempenhar competências voltadas para esse fim.

\section{Referências}

ALEXY, Robert. Teoria dos direitos fundamentais. 2. ed. São Paulo: Malheiros, 2017.

ARAÚJO, Nizete Lacerda et al. Marco legal da inovação: breves comentários. Rio de Janeiro: Lumen Juris, 2018.

ARAÚJO, Nizete Lacerda et al. Marco Legal da Inovação: breves comentários. Rio de Janeiro: Lumen Juris, 2018.

ARAÚJO, Nizete Lacerda; GUERRA, Bráulio Madureira. Dicionário de propriedade intelectual. Curitiba: Juruá, 2010.

BARBOSA, Cynthia Mendonça; ARAÚJO, Elza Fernandes de. O novo marco legal da ciência, tecnologia e inovação e os seus principais enfoques. In: ESPINDOLA, Foued Salmen; PALUMA, Thiago. Boas práticas em gestão da inovação. Curitiba: Íthala, 2017.

BARBOSA, Denis Borges et al. Direito da inovação: comentários à Lei no $10.973 / 2004$, lei federal da inovação. Rio de Janeiro: Lumen Juris, 2006.

BARBOSA, Denis Borges. TRIPS e a experiência brasileira. In: VARELLA, Marcelo Dias (Org.). Propriedade intelectual e desenvolvimento. São Paulo: Lex, 2005.

BARBOSA, Pedro Marques Nunes. Ano eleitoral e políticas públicas de propriedade intelectual. 2018. Disponível em: <https://www.migalhas.com.br/dePeso/16,MI273534,41046-Ano+eleitoral+e+politicas +publicas $+\mathrm{d}$ e+propriedade+intelectual $>$ Acesso em: 25 set. 2018.

BENETTI, Daniela Vanila Nakalski. Proteção às patentes de medicamentos e comércio internacional. In: BARRAL, Welber; PIMENTEL, Luiz Otávio (Org.). Propriedade intelectual e desenvolvimento. Florianópolis: Fundação Boiteux, 2006.

BITTAR, Eduardo C. B. Metodologia da pesquisa jurídica. 13. ed. São Paulo: Saraiva, 2015.

BOBBIO, Norberto. Da estrutura à função: novos estudos de teoria do Direito. Barueri: Manole, 2007.

BRASIL. Câmara do Deputados. Projeto de Lei no 2.177/2011. Institui o Código Nacional de Ciência, Tecnologia e Inovação. Brasília, 2011. Disponível em: <http://goo.gl/xyejaA> Acesso em: 17 jul. 2018.

BRASIL. Decreto no 5.563, de 11 de outubro de 2005. Regulamenta a Lei no 10.973, de 2 de dezembro de 2004, que dispõe sobre incentivos à inovação e à pesquisa científica e tecnológica no ambiente produtivo, e dá outras providências. Diário Oficial da República Federativa do Brasil, Brasilia, 2005. Disponível em: <http:// goo.gl/9ci03>. Acesso em: 21 jul. 2018.

BRASIL. Decreto n ${ }^{\circ}$ 9.283, de 7 de fevereiro de 2018. Regulamenta a Lei no 10.973 , de 2 de dezembro de 2004, dentre outras. Diário Oficial da União, Brasília, 2018. Disponível em: < http://www.planalto.gov.br/ ccivil_03/_ato2004-2006/2004/lei/110.973.htm>. Acesso em: 21 de jul. 2018.

BRASIL. Instituto Nacional De Propriedade Industrial. Relatório de Atividades INPI 2017. Disponível em: <http://www.inpi.gov.br/sobre/estatisticas>. Acesso em: 22 jun. 2018.

BRASIL. Lei no 10.973, de 2 de dezembro de 2004. Dispõe sobre incentivos à inovação e à pesquisa científica e tecnológica no ambiente produtivo e dá outras providências. Diário Oficial da República Federativa do Brasil, 
Brasília, DF, 3 dez. 2004. Disponível em: < http://www.planalto.gov.br/ccivil_03/_ato2004-2006/2004/ lei/110.973.htm>. Acesso em: 22 jun. 2018.

BRASIL. Lei no 13.243, de 11 de janeiro de 2016. Dispõe sobre estímulos ao desenvolvimento científico, à pesquisa, à capacitação científica e tecnológica e à inovação e altera a Lei no 10.973, de 2 de dezembro de 2004, dentre outras. Diário Oficial da República Federativa do Brasil, Brasilia, DF, 12 jan. 2016. Disponível em: <http://www.planalto.gov.br/ccivil_03/_ato2015-2018/2016/lei/113243.htm> Acesso em: 22 jun. 2018.

BRASIL. Ministério da Ciência, Tecnologia e Inovação. Política de propriedade intelectual das instituições científicas e tecnológicas do Brasil. Relatório Formict 2016. Brasilia, 2017.

BRASIL. Ministério da Ciência, Tecnologia e Inovação. Portaria no 251, de 12 de março de 2014. Brasília: MCTI, 2014. Disponível em: <http://goo.gl/SKHKdb>. Acesso em: 21 jul. 2018.

BRASIL. Palácio do Planalto. Mensagem Presidencial no 8, de 11 de janeiro de 2016. Diário Oficial da República Federativa do Brasil, Brasília: Palácio do Planalto, 2016. Disponível em: <http://goo.gl/bDLeXz>.

BRASIL. Secretaria de Assuntos Estratégicos da Presidência da República. Produtivismo includente: empreendedorismo vanguardista. Brasília: SAE/PR, 2015.

BRASIL. Senado Federal. Projeto de Lei da Câmara no 77/2015. Brasília: Senado Federal, 2015. Disponível em: <http://goo.gl/EnXv0w>. Acesso em: 21 jul. 2018.

BUCCI, Maria Paula Dallari. As políticas públicas e o Direito Administrativo. Revista Trimestral de Direito Público, São Paulo, n. 13, p. 135, 1996.

COMPARATO, Fábio Konder. Ensaio sobre o juízo de constitucionalidade de políticas públicas. Revista dos Tribunais, São Paulo, ano 86, n. 737, mar. 1997.

CRUZ, Hélio Nogueira da; SOUZA, Ricardo Fasti de. Sistema nacional de inovação e a lei da inovação: análise comparativa entre o bayh-dole act e a lei da inovação tecnológica. Revista de Administração e Inovação, São Paulo, v. 11, n.4, p. 329-354, out/dez. 2014.

DWORKIN, Ronald. Levando os direitos a sério. Tradução Nelson Boeira. São Paulo: Martins Fontes, 2002.

KANNEBLEY JÚNIOR, Sérgio; PORTO, Geciane Silveira. Incentivos fiscais à pesquisa, desenvolvimento e inovação no Brasil: uma avaliação das políticas recentes. Disponível em: <https://www.innovationpolicyplatform.org/system/files/Incentivos\%20Fiscais.pdf> Acesso em: 24 set. 2018.

ORGANIZAÇÃO PARA A COOPERAÇÃO E DESENVOLVIMENTO ECONÓMICO. Relatórios Econômicos OCDE: Brasil 2018. fev. 2018. Disponível em: < https://www.oecd.org/eco/surveys/Brazil2018-OECD-economic-survey-overview-Portuguese.pdf>. Acesso em: 21 de jul. 2018.

ORGANIZAÇÃO PARA A COOPERAÇÃO E DESENVOLVIMENTO ECONÓMICO. Relatórios econômicos OCDE: Brasil 2018. Paris: Éditions OCDE, 2018. Disponível em: <http://dx.doi. org/10.1787/9789264290716-pt>. Acesso em: 17 jul. 2018.

PALUMA, Thiago. Propriedade intelectual e direito ao desenvolvimento. São Paulo: Pillares, 2017.

PÓVOA, L.M.C. Patentes de universidades e institutos públicos de pesquisa e a transferência de tecnologia para empresas no Brasil. 2008. Tese (Doutorado em Economia) - Universidade Federal de Minas Gerais, Belo Horizonte, 2008.

PRODANOV, Cleber Cristiano; FREITAS, Ernani Cesar de. Metodologia do trabalho científico: métodos e técnicas da pesquisa e do trabalho acadêmico. 2. ed. Novo Hamburgo: Feevale, 2013.

RAUEN, C. O novo marco legal da inovação no Brasil: o que muda na relação ICT-empresa? Radar 43, p.26, fev. 2016. 
Para publicar na revista Brasileira de Políticas Públicas, acesse o endereço eletrônico www.rbpp.uniceub.br

Observe as normas de publicação, para facilitar e agilizar o trabalho de edição. 